\title{
DEL GÉNERO LITERARIO AL GÉNERO PICTÓRICO: LA TEORÍA DE LOS GÉNEROS EN LA PINTURA FRANCESA DE FÉLIBIEN A DIDEROT
}

\author{
From the Literary Genre to the Pictorial Genre: the Theory \\ of Genres in the French Painting from Félibien to Diderot
}

\author{
Jaime BLANCO APARICIO \\ Dr. en Historia del Arte. Universidad Complutense de Madrid \\ jaimeblapa@gmail.com \\ ORCID: https://orcid.org/0000-0003-0405-0411
}

Fecha de recepción: 14/10/2019

Fecha de aceptación definitiva: 3/04/2020

RESUMEN: A lo largo del cinquecento observamos un trasvase desde la noción de género literario a la teoría pictórica, paralelamente a la relectura de la Poética de Aristóteles. Este empleó las clasificaciones y los géneros retóricos para reflexionar sobre la especificidad artística, facilitando su producción y recepción posterior, constituyendo la base donde se sustentará la teoría de los géneros pictóricos en Francia, desde Félibien a Diderot. No obstante, una parte de la historiografía artística actual ha aplicado un modelo de análisis nacido en la teoría literaria del siglo XIX para analizar el fenómeno del género dieciochesco, lo que ha planteado ciertas conclusiones cuestionables a la hora de analizar la pintura del siglo XVIII. Nuestro objetivo será, por tanto, profundizar en este nacimiento de la noción de género poético y mostrar cómo se trasladó a la pintura, condicionando las clasificaciones y los géneros, y estableciendo unas jerarquías entre ellos.

Palabras clave: género literario; género pictórico; pintura francesa; Félibien; Diderot; pintura de género. 
ABSTRACT: Throughout the cinquecento we observed a transfer from the notion of literary genre to pictorial theory, simultaneously with the rereading of Aristotle's Poetics. He used classifications and rhetorical genres to reflect on artistic specificity, making easy its production and subsequent reception, being the basis on which the theory of pictorial genres in France will be sustained, from Félibien to Diderot. However, part of the current artistic historiography has applied a model of analysis born in Nineteenth-Century literary theory to study the phenomenon of the Eighteenth-Century genre, concluding with certain questionable theories, when analyzing Eighteenth-Century painting. Our aim will be therefore, to delve into this birth of the notion of poetic genre and to show how it was transferred to painting, conditioning the classifications and genres, and establishing hierarchies between them.

Key words: literary genre; pictorial genre; French painting; Félibien; Diderot; genre painting.

Los géneros son el resultado de una tendencia clasificadora del ser humano a través de la cual este busca comprender mejor el mundo en el que vive. Así, cada vez que depositamos nuestra atención en algo -al hablar o al contemplar una obra- ponemos en juego diferentes categorizaciones que tienden a establecer distintas clasificaciones. Desde un punto de vista cognitivo, al relacionarnos con la realidad sólo podemos representar las cosas a través de su identificación como «tal cosa" o "tal otra", estableciendo, por tanto, una diferenciación mediante la asignación de clases, más o menos definidas, que constituirán nuestra representación de la realidad ${ }^{1}$. La noción de género surgiría dentro de este proceso de clasificación a través del cual el hombre piensa la realidad, estando estos "marcos categoriales» socialmente determinados. Razón por la cual los géneros y las clasificaciones han ido cambiando a lo largo del tiempo y, de este modo, lejos de existir un principio cognitivo común a una época, esta dimensión social de las categorías determinará que tras toda clasificación se produzca un conflicto, ya sea de carácter estético, social o político ${ }^{2}$, que explica la inestabilidad histórica de los géneros.

Desde época temprana esta tendencia clasificadora del hombre se incorporó a la teoría artística, intentando comprender mejor la creación poética mediante su clasificación, como se observa en la Poética de Aristóteles. Sus reflexiones sobre la creación mediante el establecimiento de distintos tipos determinaron no solo la producción literaria, sino, también, la reflexión pictórica en los siglos posteriores. La recuperación de la Poética de Aristóteles durante el cinquecento originó la elaboración de diferentes clasificaciones poetológicas, considerándose

1. ShatfFer, Jean-Marie. "Système, histoire et hiérarchie: le paradigme historiciste en théorie de l'art». En RoQuE, Georges (dir.). Majeur ou Mineur? Les hiérarchies en art. Paris: Jacqueline Chambon, 2000, p. 255.

2. Blanc, Jan. "La "hiérarchie des genres". Histoire d'une notion tactique et occasionnelle». En Elsig, Frédéric et al. (eds.). Les genres picturaux. Genève: MetisPresses, 2010, p. 141. 
como un aspecto básico de toda creación, tanto literaria como pictórica, como consecuencia del principio retórico donde ambas se asentaban. Desde el siglo XVI proliferaron las clasificaciones y los géneros pictóricos, deudores de la crítica literaria aristotélica, pero no será hasta el nuevo impulso dado a la Academia francesa en 1666, con Félibien y Le Brun, cuando aquella tendencia clasificadora de la tratadística italiana adquiere un peso central dentro de la teoría pictórica francesa. Momento en el que asistimos a la elaboración de una teoría de los géneros y a una jerarquía entre ellos, que va a conformar el pensamiento pictórico francés durante los siglos XVII y XVIII.

A lo largo del cinquecento, y como leemos en Alberti, los géneros permitían a los académicos, críticos, amateurs, connaisseurs, marchantes, etc., fundamentar sus discursos artísticos y construir una forma de mirar y enjuiciar, esto es, un espectador, que es definido en este proceso, lo que explicaría su pervivencia a lo largo del siglo XIX. Así, cuando Félibien en su Préface de 1668 define los géneros pictóricos buscaba dar respuesta a tres fenómenos. En primer lugar, a las reivindicaciones de los artistas que defienden la creación de una academia que respondiese a sus anhelos de autonomía y elevación intelectual del arte frente al arte mecánico del gremio. En segundo lugar, al deseo de los amateurs por establecer un discurso que sirviese de fundamento a la crítica y que favoreciese el enjuiciamiento y recepción del arte por parte de una sociedad mundana cada vez más interesada en él. En tercer lugar, responder al interés de Colbert por reconstruir unas instituciones que diesen respuesta a las necesidades simbólicas del soberano. Su clasificación, por tanto, no fue solo una imposición desde el poder político a través de la institución académica, al situar la pintura de historia por encima del resto, sino que debemos contemplarla, también, como un intento por ordenar la producción artística y facilitar su recepción y comprensión ${ }^{3}$. De ahí que fuese ampliamente aceptada por todos aquellos que participaban en el ámbito artístico en los siglos XVII y XVIII ${ }^{4}$, desde Roger de Piles a Diderot.

Estas clasificaciones y sus géneros reflejarían, pues, una imagen del mundo, esto es, los valores, el orden y las jerarquías que imperan en él. Por ello, tras el texto de Félibien subyacía una visión del Hombre y de la Naturaleza, de su capacidad creadora y de su relación con la divinidad, etc.; que tendrá, a su vez, su reflejo en el ordenamiento de la sociedad, de sus instituciones y del arte. Solo en la medida que surgió una nueva comprensión de la Naturaleza y del Hombre a lo largo del siglo XVIII su clasificación pudo transformarse. En aquella imagen del mundo de los siglos XVII y XVIII, las pasiones ocuparon un lugar prioritario, junto al problema de su control, definiendo uno de los objetivos principales de la política

3. De forma semejante a lo ocurrido en el siglo $\mathrm{v}$ a. C., cuando los sofistas crearon las primeras clasificaciones que permitieron enseñar la technê de los discursos. Halliwell, Stephen. Aristotle's Poetics. London: Duckworth, 2009, p. 8.

4. Wrigley, Richard. The Origins of French Art Criticism. Oxford: Clarendon Press, 1995, p. 286. 
del momento: el apaciguamiento de las sociedades surgidas de la violencia religiosa a través de la elocuencia de la palabra. De ahí la centralidad ocupada por las pasiones y por la retórica en la Edad Moderna. Pero las pasiones fueron, también, uno de los fundamentos de las clasificaciones genéricas desde la Antigüedad5, como subrayó el propio Aristóteles ${ }^{6}$, y, por tanto, de la reflexión artística, como observamos en la tratadística francesa desde Félibien a Diderot ${ }^{7}$. La relación entre pasiones y géneros determinó el protagonismo ocupado por la retórica, ya que permitía pensar los discursos como una técnica enseñable, útil en muy diferentes ámbitos, como el control de las pasiones. La retórica se convirtió, así, ya desde la Antigüedad y, sobre todo, desde el cinquecento, en la base de la poética y de la teoría pictórica ${ }^{8}$, condicionando las pasiones, las clasificaciones y las jerarquías entre ellas, tal y como había subrayado Aristóteles a propósito de la superioridad de la tragedia sobre la comedia -que condicionó las clasificaciones y jerarquías tanto en la literatura como en la pintura a lo largo de la Edad Moderna-.

La función que desempeñaron las clasificaciones y los géneros en las sociedades modernas se transformó a partir del siglo xIX; y si bien hemos señalado que las clasificaciones y los géneros se desarrollan ya desde Aristóteles, sin embargo, será a partir de la teoría romántica literaria y, especialmente, con Hegel, cuando surge una teoría de los géneros propiamente dicha. Esta determinará la reflexión literaria a lo largo de los siglos XIX y XX, así como la reflexión artística en general, tendiéndose a buscar y a identificar desde entonces los diferentes géneros -cuando no a crearlos- en la historia literaria pasada, intentando a través de esta delimitación comprender la creación artística en cualquier época. Capaces de explicar la génesis formativa de cualquier obra, los géneros ocuparon un lugar central a la hora de pensar el absoluto artístico y la creación, posibilitando el nacimiento de la Historia de la Literatura y de la Historia del Arte?. Esta teoría romántica, al identificar el género con la esencia de la obra, convirtió a este en un elemento fundamental de la forma artística a partir del cual se podía penetrar -en teoríatanto en los sentidos de la propia obra de arte como de la época. Un papel que el género nunca desempeñó en las clasificaciones genéricas anteriores al Romanticismo, siendo, por tanto, ajeno a las teorías poetológicas de los siglos XVII y XVIII.

A lo largo del siglo xIx los géneros permitieron pensar la creación artística en función de la imagen del mundo decimonónica, creándose nuevos géneros y

5. Kibedi-Varga, Aron. "La rhétorique des passions et les genres». Rhetorik, 1987, 6, pp. 67-83.

6. Halliwell. Aristotle's Poetics..., p. 200.

7. Kovács, Katalin. L'Expression des passions et la biérarchie des genres dans la pensée picturale de Diderot et de ses prédécesseurs. Lille: Atelier National de Reproductions des Thèses, 2001.

8. SPENCER, John. "Ut Rhetorica Pictura: A Study in Quattrocento Theory of Painting". Journal of the Warburg and Courtauld Institutes, 1957, 20, pp. 26-44; BAXANDALL, Michael. Giotto and the Orators. London: Warburg Studies, 1971.

9. BuRCKHARDT, Jacob. Italian Renaissance Painting According to Genres. Los Angeles: Getty Research Institute, 2002. 
clasificaciones que se presentaban como universales. En la teoría pictórica aparece, así, un nuevo género: la pintura de género, que se identificó con las escenas de la vida cotidiana, lo popular o la miseria. Si bien la teoría pictórica del siglo XVIII empleó el término pintura de género, sin embargo, con él se designaba toda aquella pintura que no era de historia: retratos, naturalezas muertas, escenas de la vida, etc. Solo tardíamente, desde la Revolución y a lo largo del siglo XIX, y de forma paulatina, se convirtió en un género pictórico autónomo (en paralelo y en diálogo con las revueltas políticas y estéticas), pasando a identificarse por algunas corrientes historiográficas con las escenas populares, exclusivamente. La pintura de género se conformó como un género en sí mismo y, de acuerdo a la teoría romántica de los géneros, se consideró, igualmente, como un género ahistórico y universal, a través de cuyo surgimiento era posible penetrar en la esencia de la creación artística y de la época estudiada. A partir de estos instantes la pintura de género fue pensada a través de la teoría de los géneros ideada por el Romanticismo y las teorías estéticas decimonónicas y, de este modo, algunos historiadores del arte angloamericanos lo emplean actualmente para el análisis del fenómeno pictórico del siglo XVIII. Lo cual les ha llevado a considerar la pintura de lo cotidiano como el principal fenómeno del arte de este siglo XVIII, reflejo de las dialécticas sociales y estéticas de la centuria, utilizando herramientas de la teoría literaria del siglo XIX sobre el género como principio para el análisis pictórico del siglo XVIII.

Nuestro objetivo será a continuación, en primer lugar, mostrar la tradición teórica a partir de la cual Félibien elaboró su clasificación y su jerarquía de los géneros en pintura, determinando el pensamiento pictórico francés hasta la Revolución. En segundo lugar, mostrar cómo la creación de un género pictórico autónomo: la pintura de género, identificado con las escenas de lo cotidiano, es una invención de la tradición decimonónica ajena a los siglos analizados; lo que dificulta, además, su comprensión, al separarlo del marco de ideas donde se desarrolló. Para alcanzar tal propósito el artículo se ha dividido en tres secciones. En la primera, se hará una breve aproximación a las teorías literarias y cómo se han aplicado al estudio de la pintura francesa del siglo XVIII, dando lugar a diferentes formas de afrontar el análisis de la pintura de género. En segundo lugar, se hará un breve recorrido por la teoría de los géneros desde Aristóteles hasta la reflexión literaria del cinquecento, incidiendo en el trasvase que se produce entre la teoría de los géneros literarios y la pictórica, determinando las clasificaciones en pintura que luego se desarrollarán en Francia. En tercer lugar, se analizarán los principales textos franceses donde se ha afrontado la cuestión de los géneros en pintura, comenzando por Félibien, cuya influencia marca el siglo XVIII hasta Diderot. Frente a aquellos que pretenden observar en los textos de este el desarrollo de una nueva acepción de pintura de género próxima a la desarrollada por el siglo $\mathrm{XIX}^{10}$, estos se muestran, por contra, profundamente deudores de la teoría poetológica del siglo XVII.

10. LAVEZZI, Elisabeth. La escène de genre dans les Salons de Diderot. Paris: Hermann, 2009. 


\section{LA PINTURA DE GÉNERO, ENTRE Clasicismo y ROMANTICISMO}

En muchos estudios actuales sobre la pintura del siglo XVIII en Francia nos topamos a menudo con el término pintura de género, que es empleado para designar muy diversas cosas: escenas de lo cotidiano, una inclinación hacia la objetividad y el realismo o una pintura de temática popular opuesta a la historia. Mediante él se ha buscado explicar las transformaciones sociales de la época, pues se considera que su originalidad refleja la emergencia de un nuevo género; siendo posible descubrir a través de él una fuerza transformadora de carácter estético -característica de los géneros vulgares- que mediante diferentes mecanismos formales: conflicto, hibridación, decadencia, etc., alumbraría no solo un fenómeno estético nuevo, sino un principio de transformación social. Estos estudios tienden a mezclar, así, dos perspectivas teóricas diferentes, procedentes, una de la historia social del arte y otra de los estudios de teoría literaria. Nos encontraríamos, por un lado, un modelo de origen literario que aplica a los géneros pictóricos los análisis formalistas de la literatura, en los cuales el género ocupa un lugar central para poder explicar la transformación literaria ${ }^{11}$, pues es lo que habría posibilitado pensar el hecho literario, esto es, la poética ${ }^{12}$. Por otro lado, un modelo social del arte, heredero de las corrientes filosóficas y políticas socialistas de los siglos XIX y XX, en el que se establece que toda transformación artística -como la emergencia de una pintura de género- revela una transformación ideológica o mental que, a su vez, se enraíza en una lucha de clases donde se descubren las condiciones objetivas del cambio histórico. Ambas perspectivas van a entremezclarse en la historia del arte desde finales del siglo XIX tomando como principal principio explicativo la noción de género literario, ideado por la teoría romántica, para aplicarlo a las escenas cotidianas del siglo XVIII, como observamos en Thomas Crow o en Mark Ledbury, quienes encuentran tras las escenas de temática popular la emergencia de un nuevo género.

A lo largo de la historia literaria la noción de género ha tenido tres características principales, claramente explicitadas en el primer párrafo del capítulo primero de la Poética de Aristóteles. En primer lugar, un carácter explicativo: "Hablemos de la poética en sí y de sus especies, de la potencia propia de cada una». En segundo lugar, un carácter prescriptivo: "y de cómo es preciso construir las fábulas si se quiere que la composición poética resulte bien». En tercer lugar, un carácter descriptivo: «y asimismo del número y naturaleza de sus partes, e igualmente de

11. FOWLER, Alastair. Kinds of Literature. An Introduction the Theory of Genres and Modes. Oxford: Clarendon Press, 1982.

12. Combe, Dominique. Les genres littéraires. Paris: Hachette, 1992; Compagnon, Antoine. Théorie de la littérature: la notión de genre. Cours de M. Antoine Compagnon. Université de Paris IV-Sorbonne, 2001 [consulta: 5 de septiembre 2019]. Disponible en: https://www.fabula.org/compagnon/genre.php. 
las demás cosas pertenecientes a la misma investigación» ${ }^{13}$. Estas diferentes perspectivas a la hora de abordar el estudio de las obras han determinado la mayor parte de las clasificaciones genéricas a lo largo de la historia, pero, también, que en ellas se encuentre el germen de las distintas teorías literarias donde el género ocupa un lugar fundamental. Aunque solo la actitud esencialista (apuntada en Aristóteles, pero solo desarrollada durante el Romanticismo) ${ }^{14}$ daría lugar a una teoría de los géneros propiamente.

A partir de estos tres caracteres, Schaeffer va a establecer tres actitudes históricas: normativa, esencialista y estructural, que, a su vez, determinaron las tres principales teorías literarias que a lo largo de la historia afrontarán la noción de género. La actitud normativa dominó desde el Medievo hasta el siglo XVIII, destacando, así, las actitudes prescriptivas que podemos observar durante el humanismo italiano y durante el clasicismo francés. La actitud esencialista-evolucionista es predominante a lo largo del siglo XIX, donde se construirá un sistema genérico propiamente dicho, tal y como reflejará la tríada romántica: epopeya, drama y lírica, que constituirá el centro de la reflexión romántica sobre la literatura ${ }^{15}$. Ajena al Medievo y a la época clásica, esta actitud considera que el género es capaz de explicar la obra de arte. No busca ofrecer modelos o reglas que guíen la creación de la obra, como en el Clasicismo, sino definir unos géneros que permitan explicar la génesis y evolución de la propia literatura. Finalmente, encontraríamos la actitud estructural, que a partir de los formalistas rusos se impone en el siglo xx. Se construye sobre un carácter descriptivo y analítico del texto, creando los géneros a partir de las similitudes y diferencias entre las obras, comprendiendo toda creación dentro de un sistema ${ }^{16}$. Durante los siglos XVII y XVIII al no existir un sistema de géneros, como ha subrayado Genette, este tipo de análisis esencialista o estructural-formal que aplican algunos historiadores del arte a la pintura dieciochesca, centrándose en la irrupción o evolución de los géneros pictóricos, no tendría fundamento alguno.

No obstante, algunos historiadores del arte han considerado que una teoría de los géneros literarios podría aplicarse al estudio de la pintura, permitiendo, con ello, comprender las transformaciones formales; lo cual nos ha llevado a identificar tres usos del término 'género' por parte de los historiadores del arte del siglo XVIII. En primer lugar, se emplearía con un sentido clasificador, elaborando una simple lista con los tipos pictóricos predominantes: naturalezas muertas, retratos, pintura de historia, etc. Estas clasificaciones o bien se realizarán a partir del estudio empírico, tras analizar la producción del momento (lo que no siempre se

13. Aristóteles. Poética, 1447 a. Ed. V. García Yebra. Madrid: Gredos, 1974.

14. SHAEFfER, Jean-Marie. Qu'est-ce qu'un genre littéraire? Paris: Seuil, 1989, p. 35

15. SzOndi, Peter. Poética y filosofía de la bistoria. Madrid: Machado Libros, 1992-2005, 2 vols.

16. Tinianov, Juri. "Sobre la evolución literaria». En Todorov, Tzvetan (ed.). Teoría de la literatura de los formalistas rusos. México: Siglo XXI, 2007, p. 95. 
adecuaría bien a los imaginarios de la época, pues suele irrumpir en ella la ideología del historiador), o bien se partiría de las clasificaciones realizadas por la propia crítica artística del momento, como la clasificación de Félibien. Esta actitud clasificatoria es la que se adecuaría mejor a la propia forma de entender el género en los siglos XVII y XVIII, donde predomina una actitud clasificatoria de carácter prescriptivo y normativo.

En segundo lugar, se emplearía el término género en un sentido próximo a la teoría esencialista, la cual considera que el género es capaz de explicar el fundamento de la obra y su evolución, así como del resto de obras con las que comparte un tiempo histórico. A partir de este sistema genérico, propiamente dicho, y de la actitud historicista que lo acompaña, se favorecerá una relectura del arte del pasado, buscando en él el sistema y el género dominantes ${ }^{17}$, ya sea el drama para el siglo XIX y según Victor Hugo, o bien la pintura de lo cotidiano en el siglo XVIII, para una parte de la historiografía artística actual. Esta perspectiva confunde la clasificación prescriptiva y normativa propuesta por Félibien con un sistema genérico como el ideado por el Romanticismo, lo cual permitiría incorporar las teorías esencialistas y formalistas y poner, con ello, el acento sobre la irrupción de los géneros populares en el siglo XVIII, que son analizados desde el conflicto, la hibridación, la decadencia, etc. Esta pretensión de convertir la poética clásica en un sistema genérico la encontramos ya en el prefacio de Hugo a Cromwell $^{18}$; siendo a partir del Romanticismo cuando los modos genéricos ${ }^{19}$ (predominantes desde la Antigüedad hasta el clasicismo francés) dan paso a un sistema de géne$\operatorname{ros}^{20}$ propiamente dicho, construido en función de criterios formales, abriendo el estudio de las obras artísticas del pasado a esta nueva noción de género.

En tercer lugar, y relacionado con el anterior, se empleará el término género para designar un género específico y concreto: la pintura de género, caracterizada por sus rasgos realistas y sus referencias a la vida cotidiana. Esta noción de género sería un género en sí mismo y por antonomasia, frente a otras clases: pintura de historia, de naturalezas muertas, retratos, etc. Fue creado por la crítica artística de izquierdas a lo largo del siglo XIX, en paralelo a las teorías literarias y políticas del momento, utilizándose de forma anacrónica para analizar el arte del siglo XVIII ${ }^{21}$.

17. Jakobson, Roman. "La dominante». En Huit Questions de poétique. Paris: Seuil, 1977.

18. Hugo, Victor. «Préface». En Cromwell. Paris: Hachette, 1863, pp. 34 y 71.

19. Genette, Gérard. "Introduction à l'architexte». En GenetTe, Gérard y Todorov, Tzvetan (dirs.). Théorie des genres. Paris: Seuil, 1986, p. 142.

20. COMBE. Les genres littéraires..., p. 88.

21. Bailey, Colin; Conisbee, Philip y Gaehtgens, Thomas (coms.). The Age of Watteau, Chardin, and Fragonard. Masterpieces of French Genre Painting. New Haven: Yale University Press, 2003. 


\section{DEL GÉNERO LITERARIO AL GÉNERO PICTÓRICO}

Autores como Croce han negado que los géneros se correspondiesen con el objeto al que hacían referencia, ya que estas clasificaciones podían alargarse hasta el infinito, valorándolos como una invención de la crítica ${ }^{22}$. Sin embargo, hoy en día, en pleno renacer del interés por el discurso y la lectura, donde se inscribirían los géneros, estos demuestran su pertinencia a la hora de analizar las obras, a pesar de tratarse de una convención discursiva, ya que guían el proceso de lectura y escritura ${ }^{23}$. El primer intento por emplear el género para el análisis de las obras artísticas nace con Platón y Aristóteles, quienes en su deseo de distinguir entre los modos de expresión del ámbito poético respecto a los modos discursivos del habla cotidiana, estudiados por la Retórica, propiciaron el surgimiento de un nuevo campo de análisis específico: la Poética, en la que el género permitió analizar la obra mediante diferentes tipos clasificatorios. Fue a partir de la distinción fundamental llevada a cabo por ambos filósofos entre poesía dramática y poesía narrativa, esto es, entre narración y representación, que se definió una perspectiva prescriptiva y normativa de la creación poética, la cual se convirtió en el origen de todos los intentos por definir un sistema de géneros hasta la época romántica.

Señala Platón en su libro III de la República ${ }^{24}$ que los poetas procederán mediante formas de exposición o recitado, bien mediante narraciones puras ( $h a$ plè diègèsis), o bien mediante imitación (mímesis) ${ }^{25}$. Platón no habla de géneros literarios, sino, más bien, de modalidades de enunciación ${ }^{26} ;$ y, así, mientras Platón prefiere las narraciones puras (haplè diègèsis), excluyendo a los géneros imitativos (como la tragedia, la comedia o la epopeya, de acuerdo a su filosofía del conocimiento), Aristóteles, por el contrario, elaborará su reflexión sobre las formas miméticas (que constituirán el núcleo de su Poética), donde la representación, ficción o mímesis de las acciones humanas se convierten en el núcleo principal de su clasificación. Aristóteles otorgaba, así, al contenido (y no a la forma de enunciación o narración, como sucede en Platón) el lugar preponderante a la hora de analizar las obras de $\operatorname{arte}^{27}$ (tal y como veremos en Félibien). Sobre estas premisas la tragedia se convirtió en el género por excelencia de la Poética, influyendo en el devenir posterior de la reflexión poetológica, que se centrará en los problemas de la mímesis y de la representación. Frente al análisis platónico centrado en los

22. Croce, Benedetto. Estetica come scienza dell'espressione e linguistica generale. 3. ${ }^{a}$ edición. Bari: Laterza, 1908, p. 44.

23. Compagnon. "Deuxième Leçon: Norme, essence ou structure?». En Théorie de la littérature...

24. Platón. República, III, 392 d. Ed. C. Eggers. Madrid: Gredos, 2000.

25. GenetTe. "Introduction à l'architexte...", p. 96; GenetTe, Gérard. "Frontières du récit». En Figures II. Paris: Seuil, 1969, p. 51.

26. SHAEFFER. Qu'est-ce qu'un genre littéraire?..., p. 12.

27. «El poeta debe ser artífice de fábulas más que de versos, ya que es poeta por la imitación, e imita las acciones. Y si en algún caso trata cosas sucedidas, no es menos poeta». Aristóteles. Poética, $1451 \mathrm{~b}$ 
modos de exposición -o formas del discurso-, Aristóteles hablará de géneros, entendiéndolos como aquellas especies definidas según sus finalidades propias, esto es, según su esencia: "Hablemos de la poética en sí y de sus especies, de la potencia propia de cada una ${ }^{28}$. Los géneros quedaban articulados, de este modo, en torno a la cuestión de la mímesis, diferenciándose entre sí en función de los medios de representación, los objetos de representación y los modos de representación ${ }^{29}$; a partir de los cuales se definirán los géneros o especies. Aunque solo estudiará la tragedia.

En ambos filósofos el género ocupa un lugar importante, pero no era una noción que permitiera sistematizar una visión de conjunto sobre la producción literaria y, por tanto, a través de ella no era posible formular la pregunta por la esencia de lo literario, tal y como planteará el romanticismo (a pesar de que Aristóteles habló de "la potencia de cada una»). El empleo de la noción de género sería más bien asistemático, predominando una actitud prescriptiva ${ }^{30}$. De este modo, el periodo que va desde la Antigüedad postaristotélica hasta finales del siglo XVIII se caracterizó por una actitud clasificatoria, donde se inscribe la teoría pictórica francesa, pudiéndose establecer, a su vez, cuatro tipos predominantes: a) la actitud de clasificación en árbol, según una distinción de género y especie; b) la actitud de enumeración empírica; c) la actitud normativa; d) la teoría de los niveles de estilo ${ }^{31}$.

La obra de Aristóteles fue interpretada por los autores posteriores, como Horacio, acentuando la dimensión moral y placentera de la poesía ${ }^{32}$, lo que era ajeno a la Poética. Se favoreció, con ello, una lectura retórica, cuando precisamente Aristóteles había intentado distanciarse de esta para dotar de entidad propia a los discursos poéticos ${ }^{33}$. Al favorecer una poetización de la retórica, Cicerón y Horacio provocaron una 'retorización' de la poética. Razón por la cual desde el Medievo los géneros poéticos fueron pensados frecuentemente a partir de los estilos del discurso del orador ${ }^{34}$. La predominancia de Horacio durante el Renacimiento condicionó igualmente la recepción y recuperación de Aristóteles ${ }^{35}$, pensándose la poesía a partir de los efectos causados en el espectador, lo cual acentuó la importancia de los géneros originalmente desarrollados en la retórica ${ }^{36}$ en los estudios de poética. Esta comprensión retórica de la poética posibilitaba, por un lado, una

28. Ibid., 1447 a.

29. "Pero se diferencian entre sí por tres cosas: o por imitar con medios diversos, o por imitar objetos diversos, o por imitarlos diversamente y no del mismo modo". Ibid.

30. SHAEFFER. Qu'est-ce qu'un genre littéraire?..., p. 18.

31. Ibid., pp. 25 y s.

32. Horacio. Arte Poética, 340. Ed. J. Moralejo. Madrid: Gredos, 2008.

33. Halliwell. Aristotle's Poetics..., p. 8.

34. CurTius, Ernst. Literatura europea y Edad Media latina. México: FCE, 1976, t. 1, p. 328.

35. WeInBERG, Bernard. A History of Literary Criticism in the Italian Renaissance. Chicago: The University of Chicago Press, 1961, cap. IV, pp. 111 y s.

36. PEPE, Cristina. The Genres of Rhetorical Speeches in Greek and Roman Antiquity. Leiden: Brill, 2013. 
moralización del arte; por otro lado, el establecimiento de unas reglas para la creación; y, finalmente, pensar de forma global las artes más allá de la epopeya y la tragedia ${ }^{37}$. Además, al ocupar la retórica un lugar central en el sistema educativo humanista, todas las artes se encontraban relacionadas con ella, definiendo un lenguaje común para todas -como había subrayado Quintiliano-, favoreciendo el trasvase entre literatura y pintura durante el cinquecento $^{38}$. Al incorporarse la jerarquía retórica al análisis de la obra pictórica, por ejemplo, a nivel de organización y composición $^{39}$, se favoreció el trasvase de la noción de género y sus clasificaciones desde la poesía a la pintura, convirtiéndose en uno de los elementos centrales de la reflexión pictórica. En estos instantes también asistimos a la poetización de la retórica, poblándose de metáforas pictóricas las reflexiones sobre los discursos: "Le discours est une peinture de nos pensées: la langue est le pinceau qui trace cette peinture et les mots son les couleurs" ${ }^{40}$.

El principal pasaje de la Poética al que habitualmente aludieron sus comentaristas para fundamentar la existencia de géneros pictóricos fue aquel en el que, a propósito de los objetos imitados, Aristóteles puso en relación el poema y la pintura:

Mas, puesto que los que imitan, imitan a hombres que actúan, y éstos necesariamente serán esforzados o de baja calidad (los caracteres, en efecto, casi siempre se reducen a éstos solos, pues todos sobresalen, en cuanto al carácter, o por el vicio o por la virtud), o bien los hacen mejores que solemos ser nosotros, o bien peores o incluso iguales, lo mismo que los pintores. Polignoto, en efecto, los pintaba mejores; Pausón, peores, y Dionisos, semejantes ${ }^{41}$.

Para poder aclarar el sentido de este fragmento -y del conjunto de la Poéti$c a-$ se consideró que era necesario conocer aquella pintura de la que no parecía haber quedado huella alguna, por lo que tuvieron que volver su mirada hacia la pintura del siglo XVI, tal y como observamos en Trissino, favoreciendo el trasvase desde las categorías aristotélicas a la pintura:

Essendo adunque tutti gli uomini per vizj, o per virtù, tra se ne li loro costumi differenti, è necessaria cosa farli overo migliori, overo come sono quelli de la nostra

37. Kibedi-Varga, Aron. Les poétiques du classicisme. Paris: Klincksieck, 1990, p. 14.

38. HENIN, Emanuelle. "Ut pictura theatrum". Théâtre et peinture de la Renaissance italienne au classicisme français. Genève: Droz, 2003, p. 126.

39. "Aconsejo al pintor estudioso que se haga familiar y bienquerido para poetas, oradores y los otros doctos en letras, pues de esos ingenios eruditos obtendrán no sólo óptimos ornamentos, sino que también irá en provecho de sus invenciones». AlBerTi, Leon Battista. "De la Pintura, III, 54». En De la pintura y otros escritos sobre arte. Madrid: Tecnos, 2007, p. 115.

40. LAMY, Bernard. L'Art de parler. Paris: André Pralard, 1675, p. 4.

41. ARISTóteles. Poética, 1448 a. 
età, overo peggiori, come fanno alcuni Pittori, de li quali il Vinci imitava i migliori, il Montagna i peggiori, e Tiziano gli fa simili42 ${ }^{42}$

Los comentaristas querían saber sobre qué fundamentaba Aristóteles su clasificación, si sobre el contenido o sobre la forma, esto es, en las costumbres y el estatus social o en la forma de la representación ${ }^{43}$, tal y como se refleja en Roborte$1 \mathrm{l}^{44} \mathrm{O}$ en Minturno ${ }^{45}$. En el mismo capítulo Aristóteles añadía: «Y la misma diferencia separa también a la tragedia de la comedia; ésta, en efecto, tiende a imitarlos peores, y aquélla, mejores que los hombres reales ${ }^{46}$. Esta distinción entre tragedia y comedia, unida a la relación entre poesía y pintura, se trasladó a la reflexión pictórica, donde se diferenciaron dos grandes grupos, una pintura que muestra a los personajes mejores de lo que suelen ser y otra que los muestra peores, adscribiéndose esta última a la comedia: "Los poetas cómicos pintan no sólo los esclavos, los parásitos y las prostitutas, sino también aquellos que se encuentran en un modesto estado de fortuna ${ }^{47}$. Se favoreció, así, el traslado de los géneros literarios a los géneros pictóricos, considerando a estos, además, como fundamentales para comprender aquellos; y, de este modo, se acudió a aquellos textos de la Antigüedad que permitían aclarar el texto aristotélico, ya que describían la pintura antigua. Plinio el Viejo, en su libro XXXV de su Historia Natural, daba indicaciones sobre la pintura antigua que permitía fundamentar mejor las clasificaciones poéticas y pictóricas al describir detalladamente la pintura, por ejemplo, del pintor Piraeicus, quien se había especializado en una pintura menor de temas sórdidos o rhyparographos ${ }^{48}$. Pronto esta se identificó con aquel tipo de pintura que hacía

42. Trissino, Giovan Giorgio. «Sei Divisioni della Poetica. La Quinta divisione». En Tutte le Opere di Giovan Giorgio Trissino. Verone: Jacopo Vallarsi, 1729, t. II, p. 94.

43. "Ne è vero, che gli huomini rassomiglianti rassomiglino gli huomini occupati in attione per iscoprire i costumi, come non oscuramente pare, che vogliano significare le parole d'Aristotele li quali constumi sono compagni apparenti [...] la cual poesia si distingue in diverse spetie no per bonta, o per malvagita de costumi delle persone, che sono elette dal poeta da rassomigliare, ma per gli stati delle persone o reali, o cittadine, o contadine, \& havendo rispetto a quelle s'eleggono principalmente le favole convenevoli alla loro conditione, che non sono altro, che attioni non avenute, ma possibili advenire non per iscoprire i costumi o la bonta, o la malvarita, ma per dilettare con la novita del caso". Castelvetro, Ludovico. Poetica d'Aristotele, I, 6. Basilea: Pietro de Sedabonis, 1576, p. 35.

44. «Polignoto representaba a los más nobles, Dionisio a los que eran semejantes, Pausón a los peores. Los pintores dan forma a los más nobles, cuando representan a los héroes o a aquellos varones que no se encuentran en nuestro tiempo [...] Unos pintan aquello que es práctica común de su tiempo [...] Otros pintan muy bien lo que es menos noble [...] Tales son los pintores que pintan a los hombres practicando el coito o distorsionando la boca e hinchando los carrillos». ROBORTELLO, Francesco. Comentario a la Poética de Aristóteles. Ed. J. Bermúdez. Salamanca: Ediciones Universidad de Salamanca, 2016, p. 89.

45. Minturno, Antoinio. L'Arte Poetica del signor Antonio Minturno. Napoli: Gennaro Muzio, 1725 , p. 2.

46. ARISTÓteles. Poética, 1448 a

47. Minturno, Antonio. De Poeta. Venezia, 1559, p. 24. Traducción propia.

48. PLINIO. Natural History, XXXV, 112. Ed. Loeb. Cambridge: Harvard University Press, pp. 343 y s. 
alusión a la vida cotidiana y, por tanto, de los dos géneros descritos por Aristóteles con la comedia, heredando sus prejuicios.

La teoría de los estilos retóricos de Cicerón fue otro de los textos que contribuyeron a la definición de los géneros, siendo la base del texto de Demetrio Sobre el estilo donde, al escribir sobre el pintor Nicias, establece una jerarquía en pintura diferenciando entre los temas menores, como pequeños pájaros o flores, y los temas elevados, como batallas navales y cargas de caballería ${ }^{49}$. El tratado de Vitruvio, a través de sus reflexiones sobre los espacios arquitectónicos y los tipos de pintura $^{50}$, distinguió entre una pintura decorativa, más ilusionista, destinada a las casas de campo, y una pintura de historia destinada a las arquitecturas públicas. Su clasificación no se definía en torno al ideal/real ni a lo elevado/bajo, sino entre animada o inanimada, mostrando la estrecha relación entre las pasiones y los géneros. El propio Vitruvio establecía, además, un paralelismo entre los géneros teatrales y los tipos de escenas, profundizando en el diálogo entre poesía y pintura:

Tres son las clases de escenas: trágicas, cómicas y satíricas; sus decorados son muy diferentes entre sí por diversas razones; las tragedias se representan con columnas, fastigios, estatuas y otros elementos regios; las comedias poseen el aspecto de edificios privados con balcones y ventanas, que simulan edificios ordinarios; las satíricas se adornan con árboles, cuevas, montañas y otras características propias del campo que imitan paisaje ${ }^{51}$.

Alberti distinguirá tres tipos de pintura que identifica con tres géneros poéticos: noble, medio y elevado -siguiendo los estilos retóricos-; y que, a su vez, vincula a los tres géneros dramáticos: tragedia, comedia y pastoral, identificando cada acción y costumbre con cada tipo de monumento.

Y, dado que la temática de la pintura, como la de la poesía, es diversa -en unos temas se conmemoran las hazañas de los príncipes más poderosos, en otros se tratan las costumbres de ciudadanos individuales, en otros la vida campesina-, la temática citada en primer lugar, que es la que conlleva mayor dignidad, se aplicará a las obras públicas y a las construcciones de los personajes más relevantes; la citada en segundo lugar, por el contrario, se empleará como elemento ornamental en los muros pertenecientes a los ciudadanos particulares; mientras que la citada en último lugar será la más adecuada para los jardines, por ser la más alegre de todas ${ }^{52}$.

La teoría arquitectónica y escenográfica, desde Vitruvio a Serlio, al asociar géneros dramáticos y escenas pictóricas terminó por crear una nueva distinción entre pintura decorativa y pintura de historia, susceptible de integrarse en las teorías y clasificaciones pictóricas, como observamos en Paleotti, Lomazzo o Armenini. El

49. Demetrios. On Style, 75-78. Ed. Loeb. Cambridge: Harvard University Press, 1995, p. 399.

50. Vitruvio. Los diez libros de Arquitectura, 7, V. Ed. J. Oliver. Madrid: Alianza, 2000, p. 273.

51. Ibid., 5, VI, p. 208.

52. Alberti, Leon Battista. De Re Aedificatoria, IX, 4. Ed. J. Fresnillo. Madrid: Akal, 1991, p. 380. 
propio Lomazzo distingue en su Trattato entre comedia y tragedia, oponiendo, al didactismo y heró́smo de esta, los temas ligeros y depravados de las tabernas de aquella, identificando ciertos espacios de tabernas con cierto tipo de pintura y con aquellos pintores que las frecuentaban ${ }^{53}$.

En este trasvase desde los géneros poéticos hacia los géneros pictóricos podemos destacar dos caminos. Por un lado, aquel influenciado por los estilos retóricos, donde lo importante no es tanto el objeto imitado sino el tono empleado, lo que permitía que en un mismo cuadro se empleasen distintos estilos para cada una de las partes del cuadro, posibilitando una teoría sobre la mezcla de géneros o estilos. Por otro lado, aquel influenciado por la Poética aristotélica que abogaba por la distinción nítida entre comedia y tragedia, esto es, entre diferentes temas. Esta defensa de la pureza del género se observa en Francia en los debates sobre la tragicomedia que darían lugar a la Querelle du Cid, influyendo, a su vez, en la teoría pictórica desde Félibien a lo largo del dieciocho: "Une circonstance si basse et si burlesque est indigne de la majesté du sujet et donne absolument dans le petit. C'est mêler le bas comique au tragique le plus touchant, et mettre un pied dans le cothurne et l'autre dans l'escarpin " ${ }^{54}$.

Las clasificaciones, tanto en poesía como en pintura, profundizaron en la distinción entre tragedia y comedia, remarcando la superioridad de la primera: «Unos, en vez de yambos, pasaron a hacer comedias, y los otros, de poetas épicos se convirtieron en autores de tragedias, por ser estas formas de más fuste y más apreciadas que aquéllas" ${ }^{55}$; lo que determinó que desde finales del cinquecento ciertos temas o géneros se consideraran superiores moralmente a otros, favoreciendo la teorización de unos en detrimento de otros. A pesar de lo cual, la recuperación de la Poética también despertó el interés por la comedia, desarrollándose una teoría sobre lo ridículo y lo cómico ${ }^{56}$ que favorecerá la promoción de determinados temas como eran las escenas de lo cotidiano, surgiendo en la pintura una vía cómica $^{57}$. Esta se explorará mediante dos vías. En primer lugar, la deformación, vinculada, a su vez, a la idea de grotesco. En segundo lugar, la mímesis fidedigna: «Se regardant dans cette comédie comme dans un miroir, l'homme peut, s'il a l'âme laide, se faire beau; et s'il a l'âme belle, se faire beaucoup plus beau, comme disait Socrate ${ }^{58}$. A finales del siglo XVI se observa, pues, el surgimiento de unas

53. Lomazzo, Giovanni Paolo. Trattato dell'arte della pittura..., VI, 27. Roma: Saverio Del-Monte, 1844 , p. 199.

54. Coypel, Antoine. Discours prononcez dans les Conférences... Paris: Jacques Collombat, 1721, p. 69.

55. ARISTÓteles. Poética, 1449 a.

56. Herrick, Marvin. Comic Theory in the Sixteenth Century. University of Illinois Press, 1964.

57. BATTisti, Eugenio. L'Antirinascimento. Roma: Fletrinelli, 1962, pp. 278-313.

58. SECCHI, Nicolo. L'Interesse. Venise: Ziletti, 1581. Citado en HÉNIN. "Ut pictura theatrum»..., p. 126. Es importante subrayar que la producción pictórica reflejó siempre una gran variedad temática que nunca se correspondió literalmente con las clasificaciones elaboradas por los géneros literarios. 
escenas interesadas en lo cotidiano y en la realidad, sin idealización alguna, que no pueden entenderse ni como una pretensión de desarrollar realismo alguno ${ }^{59} \mathrm{ni}$ como una respuesta pictórica a la comedia ${ }^{60}$. Aunque muchos teóricos de la época la vinculasen a lo cómico.

Estas escenas de la vida cotidiana se producirán en unos instantes que algunos han descrito como un Counter-Renaissance ${ }^{61}$. Una especie de otoño ${ }^{62}$, visible en la Lombardía de la Accademia dei Facchini della Val di Blenio y de Lomazzo ${ }^{63}$, donde emerge una cultura de lo grotesco y de lo popular, de lo carnavalesco y del culto báquico y dionisiaco, en el que se entremezcla lo erótico con el furor creativo platónico, que tomará forma en la Roma de Caravaggio. Coincidirá con un momento en el que, tras la Reforma de la Iglesia católica, comienza a desarrollarse un interés por conocer los problemas de la sociedad y por el control de las poblaciones ${ }^{64}$. Reflejado en el interés despertado por ciertas temáticas vinculadas al pauperismo, descubriéndose, además, un interés por esos otros mundos, en paralelo al proceso de confesionalización.

Ya desde el quattrocento se observa en la Italia del norte una inclinación hacia las escenas de lo cotidiano ${ }^{65}$, aunque será en el cinquecento cuando conquistarán su independencia. La llegada a Roma desde Lombardía de autores como Caravaggio y Carracci, así como la afluencia de pintores del norte de Europa, favorecerán en la Roma de comienzos del XVII el desarrollo de una pintura de escenas de la vida que encontrarán en Peter van Laer -il Bamboccio- una traducción figurativa que gozará de gran predicamento entre los coleccionistas y entre los jóvenes pintores que llegan a la ciudad a formarse. Estas escenas de lo cotidiano se conformarían a partir de diversas tradiciones y géneros pictóricos preexistentes $^{66}$, caracterizándose por el abandono del tono cómico-grotesco a favor de una visión naturalística que coincidirá con el despertar de la curiosidad etnográfica hacia ciertos colectivos de la ciudad. Se observa, así, una actitud

59. Briganti, Guiliano. "Il mito della "finestra aperta"». En Briganti, Guilano; Trezzani, Ludovica y LaUReati, Laura (coms.). I Bamboccianti. Roma: Ugo Bozzi, 1983, pp. 1-36.

60. PORZIO, Francesco (com.). Da Caravaggio a Ceruti. La scena di genere e l'immagine dei pitocchi nella pittura italiana. Brescia: Museo di Santa Giulia, 1998.

61. HAYDN, Hiram. The Counter-Renaissance. New York: Harbinger Book, 1950.

62. Ossola, Carlo. Autunno del Rinascimento. 'Idea del Tempio' dell'arte nell'ultimo Cinquecento. Firenze: Olschki, 2014.

63. KaHn-Rossi, Manuela y PORZIO, Francesco (coms.). Rabisch/Arabeschi. Il grottesco nell'arte del Cinquecento: l'Accademia della Val di Blenio, Lomazzo e l'ambiente milanese. Lugano: Museo cantonale d'art di Lugano, 1998.

64. Delumeau, Jean. Vie économique et sociale de Rome dans la seconde moitié du XVI siècle. Paris: De Broccard, 1957-1959, 2 vols.

65. Aikema, Bernard y Brown, Beverly Louise (coms.). Il Rinascimento a Venezia e la pittura del Nord ai tempi di Bellini, Dürer, Tiziano. Venezia: Palazzo Grassi, 1999. p. 78

66. PORZIO, Franceso. Pitture ridicole. Scene di genere e tradizione popolare. Milano: Skira, 2008, 
descriptiva y un cierto gusto por la crónica y por los sucesos de la ciudad que se materializarían en la atención hacia el mundo de las calles y de las tabernas, de los pícaros, de los pobres, de los zíngaros, de los delincuentes, etc.; y que, originalmente inspirados en los modelos del norte, están viviendo una redefinición en el mundo romano.

La difusión de estas bambochadas -dentro y fuera de Italia- ${ }^{67}$ se producirá en unos años complejos de la política italiana, tras el fin del pontificado Barberini y el comienzo de la austeridad del pontificado de Inocencio X. Quizás, por ello, la crítica artística tenderá a valorarlas de forma negativa, pues, entre otras razones, su éxito se produjo gracias a un mercado artístico dominado por los marchantes que venía a sustituir la tradicional relación academia-poder, donde se había sustentado hasta ahora la dignidad de la pintura. Se consideró, así, que sus temas indignos venían a cuestionar los valores intelectuales y liberales de la pintura ${ }^{68}$, proviniendo los ataques, sobre todo, de los teóricos adscritos a la escuela boloñesa. Críticos como Bellori o Malvasía, en su deseo de encumbrar la pintura de los boloñeses Carracci y Sacchi, se muestran opuestos a Caravaggio y a los bamboccianti, empleando la noción de géneros en sus luchas estéticas ${ }^{69}$, lo que se trasladará a Francia $^{70}$.

La emergencia de una estética idealista y las teorías de la bella naturaleza, durante el siglo XVII, ayudarán a definir una jerarquía de los géneros ${ }^{71}$, siempre sobre la base de Aristóteles, tendiéndose a contraponer un arte ideal, representado por Rafael, a un arte basado en la realidad de autores como Bassano:

Considerando Aristotile [...] Ma a'nostri tempi Rafaelle, e la Scuola Romana di quel secolo, come du sopra si è detto, seguendo le maniere delle Statue antiche, hanno

67. SPIKE, John (com.). Giuseppe Maria Crespi and the Emergence of Genre Painting in Italy. Fort Worth: Kimbell Art Museum, 1986.

68. CASTiglione, Julia. «Salvatore Rosa contre les Bamboccianti. La querelle de la dignité de l'art». En Lemoine, Annick (com.). Les Bas-fonds du baroque. La Rome du vice et de la misère. Roma: Académie de France à Rome, 2015, pp. 111-115.

69. "A V.S. non sarà discaro sapere che fra le cose declinanti in Roma, è la pittura, li dico che avendo veduto quanto in alto sia la cognizione del vero bello della natura e quanto difficile il rappresentarlo con la convenevole nobilità degli accidenti, e l'espressioni prorprie con decoro, si sono pigliate una certa libertà di conscienza in rappresentare il tutto e mal fondato nel vero con fare atti sconci, ed inconvenevoli, senza cognizione di grazie, e decoro". SACCHI, Andrea. "Carta de Andrea Sacchi a Francesco Albani, Roma, 28 de octubre de 1651». Citada en Briganti et al. I Bamboccianti..., p. 352.

70. Bonfait, Olivier (dir.). L'idéal classique. Les échanges artistiques entre Rome et Paris au temps de Bellori (1640-1700). Paris: Somogy, 2002.

71. "Anzi la natura, per questa cagione, è tanto inferiore all'arte, che gli artefici similitudinarii e del tutto imitatori de' corpi, senza elezzione e scelta dell'idea, ne fuorono ripresi: Demetrio ricevé nota di esser troppo naturale, Dionisio fu biasimato per aver dipinto gli uomini simili a noi, communemente chiamato [anthropographos], cioè pittore di uomini. Pausone e Pirreico furono condannati maggiormente, per avere imitato li peggiori e li piú vili, come in questi nostri tempi Michel Angelo da Caravaggio fu troppo naturale, dipinse i simili, e l'Bamboccio i peggiori». BeLLori, Giovan Pietro. Le vite de' pittori scultori e architetti moderni. Ed. E. Borea. Torino: Einaudi, 2009, t. I, pp. 15-16. 
sopra gli altri imitati i migliori; \& il Bassano è stato un Pierico nel rassomigliare i peggiori: \& una gran parte de' moderni, hà figura gli eguali; e fra questi il Caravaggio eccellentissimo nel colorire si dee comparare à Demetrio, perche hà lasciato indietro l'Idea della belleza, disposto di seguire del tutto la similitudine ${ }^{72}$.

A medida que las ideas de Aristóteles se consolidan en la teoría pictórica, la acción representada ${ }^{73}$ predominará sobre los caracteres, esto es, sobre los aspectos físicos o morales de los personajes, es decir, sobre si estos eran representados mejor, igual o peor. La acción pasó a definir los distintos géneros y, de este modo, mientras la tragedia se caracteriza por el hombre en acción, la comedia lo hará por la ausencia de acción. El teórico Giulio Mancini ${ }^{74}$ propondrá, así, una clasificación en función de la animación, comenzando por el paisaje, continuando por el retrato (donde distingue entre ritratto con acione y ritratto semplice, como ya había apuntado Giorgione) y finalizando en la pintura de historia. Estas ideas, junto a las desarrolladas por Giustiniani ${ }^{75}$, quien distingue doce clases de pintura por su dificultad creciente, las encontraremos de nuevo en la clasificación y jerarquía de los géneros que llevará a cabo Félibien.

\section{La ACAdemia y la Jerarquía de los GÉNEROS en Pintura, De FÉlibien a Diderot}

En Francia los géneros ocuparon también un lugar destacado a la hora de pensar el arte, pudiéndose destacar dos momentos claves vinculados a la fundación de academias. En primer lugar, en el ámbito literario, a propósito de los debates surgidos en los años 30 entre regulares e irregulares ${ }^{76}$ y en relación a la tragicomedia (tras las que subyacía un deseo político por controlar los debates en un momento en que se funda la Academia de Letras), que finalizarán con el establecimiento de unas normas o principios que debían guiar la creación y en la que la clasificación en géneros desempeñó un papel destacado ${ }^{77}$. Se buscó, así,

72. Agucchi, Giovanni Battista. Trattato. Citado en Mahon, Denis. Studies in Seicento Art and Theory. Wesport: Greenwood Press, 1971, pp. 255-257.

73. «Además, sin acción no puede haber tragedia; pero sin caracteres, sí. En efecto, las tragedias de la mayoría de los autores modernos carecen de caracteres, y en general con muchos poetas sucede lo mismo, como también entre los pintores le ocurrió a Zeuxis frente a Polignoto; este, en efecto, es buen pintor de caracteres, mientras que la pintura de Zeuxis no tiene ningún carácter». ARISTótelEs. Poética, 1450 a.

74. Mancini, Giulio. Considerazioni sulla pittura. 1620. Roma: Accademia dei Lincei, 1956, 2 vols.

75. Giustiniani, Vincenzo. Discorso sopra la pittura. 1620. En Discorsi sopra le arti e mestieri. Firenze: Sansoni, 1981.

76. Dotoli, Giovanni. Temps de Préfaces. Le débat théâtrale en France de Hardy à la Querelle $d u$ "Cid». Paris: Klincksieck, 1996.

77. «La Poétique générale peut être distinguée en trois espèces de poème parfait, en l'épopée, la tragédie, la comédie, et ces trois espèces peuvent se réduire à deux seulement, dont l'une cosiste dans la représentation, l'autre dans la narration [...] Car le sonnet, le madrigal, l'épigramme, le rondeau, 
la claridad y la transparencia de los géneros, definiendo unas estrictas jerarquías dentro de los sistemas taxonómicos ${ }^{78}$ que condicionaron la reflexión pictórica posterior. En segundo lugar, la fundación de la Academia de Pintura y Escultura que tras complejos avatares ${ }^{79}$ no logró consolidarse hasta 1664, con el nombramiento de Colbert como Surintendant des Bâtiments. Momento en el que la Academia pudo elaborar unos principios teóricos -redactados por Félibien- en los que la clasificación de la pintura en base a unos géneros se instituyó como un principio básico de la reflexión pictórica.

Uno de los rasgos del gobierno de Richelieu fue la progresiva supeditación de los hombres de letras al poder monárquico, a través de un sistema de subvenciones y ayudas ${ }^{80}$, que culminará con la creación de la Academia de Letras. Su sucesor Mazarino desatenderá esta cultura de Estado, al comprender la propaganda artística de una forma más personalista, lo que generó una incertidumbre entre los hombres de letras que se acentuó con la Fronda. Ante la disolución de los círculos mundanos y a pesar de la inestabilidad política y la crisis económica, Mazarino no consideró como una necesidad el sostenimiento de los hombres de letras, lo que les obligó a buscar otras fuentes de patrocinio ${ }^{81}$ entre la nobleza y hombres de la robe. La política de panfletos y libelos que se desencadenó durante la Fronda: las mazarinadas, demostraría, por contra, la necesidad de ejercer un mecenazgo desde el Estado. Así, Colbert, a mediados de los años 50, presentó a Mazarino dos listas con poetas, filósofos, etc., para reconstruir el mecenazgo estatal, pero la falta de dinero hizo fracasar la empresa. Los nuevos surintendants de Mazarino, Servien y Fouquet, iniciaron diversos proyectos de mecenazgo privado, a la altura del ejercido por Richelieu ${ }^{82}$, logrando Fouquet reunir en su castillo de Vaux-le-Vicomte algunos de los principales representantes de las artes del momento, lo que animó, finalmente, a Mazarino a reactivar el mecenazgo estatal.

Algunos de los hombres que protagonizaron las principales empresas artísticas del XVII trabajaron previamente en Vaux, siendo, asimismo, el lugar donde coincidieron los protagonistas de la llamada Petite Académie A $^{83}$, como Charles Perrault o Jean

la ballade, ne son que des espèces de poème imparfait». RAPIN, René. Reflexions sur la poétique de ce temps. Paris: Claude Barbin, 1675, p. 77.

78. Kibedi-VArga. Les poétiques du classicisme..., p. 11.

79. Michel, Christian. L'Académie Royale de Peinture et de Sculpture. Genève: Droz, 2012.

80. Ranum, Orest. Artisans of Glory: Writers and Historical Thought in Seventeenth-Century France. North Carolina: Chapel Hill, 1980.

81. Bannister, Mark. "The Crisis of Literary Patronage in France, 1643-1655». French Studies, 1985, 39, pp. 18-30.

82. CARriER, Hubert. "La victoire de Pallas et le triomphe des Muses? Esquisse d'un bilan de la Fronde dans le domaine littéraire». Revue XVII siècle, 1984, 145, pp. 363-376.

83. Gros DE Boze, Claude. Mémoires de littérature tires des registres de l'Académie Royale des Inscriptions et Belles-Lettres. Paris: Imprimerie Royale, 1759, 25 vols.; MAURY, Alfred. L'ancienne Académie des Inscriptions et Belles-Lettres. Paris: Didier, 1864; MELET-SANSON, Jacqueline. "La petite Académie 
Chapelain ${ }^{84}$. Sobre ella se apoyará Colbert para reformular la Academia de Pintura y Escultura en 1663, de forma similar a como había hecho Richelieu respecto a la Academia de Letras a partir del núcleo de Valentin Conrart ${ }^{85}$. Este conocía a Félibien desde finales de los años 40 y mantenía estrechos contactos, a su vez, con Perrault y Chapelain ${ }^{86}$, por lo que Félibien entra en contacto en Vaux -probablemente vía Conrart- con los principales teóricos de la literatura francesa y con Charles Perrault, incorporándose gracias a este al círculo de Colbert, con quien mantenían una estrecha relación ${ }^{87}$. También coincidirá en Vaux con Le Brun, figura clave en la futura Academia, que se encontraba decorando el palacio. Toda esta red de relaciones, así como sus textos sobre la decoración de Vaux, ayudaron a Félibien a ser elegido por Colbert como historiógrafo de los edificios del rey ${ }^{88}$. Entraba, con ello, de lleno en el proyecto de engrandecimiento de la monarquía, que buscaba desarrollar una estrategia discursiva apoyada sobre la capacidad narrativa y elocuente de la imagen, construida a partir de la acción y expresión de los cuerpos mediante la cual lograr la emoción del espectador. Una búsqueda que coincidía con la estrategia desplegada por el propio Félibien en sus escritos sobre la compleja decoración alegórica que estaba llevando a cabo Le Brun en Vaux. Ambos autores estaban reformulando en Vaux la pintura francesa creando un grand format ${ }^{89}$ que atrajo rápidamente la atención de Colbert. Aunque no será hasta la consolidación de las conferencias en la Academia, sobre la base de los modelos de la écfrasis antigua ${ }^{90}$, que Francia logró crear una teoría propia ${ }^{91}$.

ou Académie des Inscriptions et Belles Lettres». En Colbert 1619-1683. Paris: Hôtel de la Monnaie, 1983, pp. 447-455.

84. FABRE, L'abbé A. Chapelain et nos deux premières académies. Paris: Perrin, 1890; ColLAS, Georges. Un poète protecteur des lettres au XVII siècle. Jean Chapelain (1593-1674). Paris: Perrin, 1912.

85. SCHAPIRA, Nicolas. Un professionel des lettres au XVII siècle. Valentin Conrart, une bistoire sociale. Seyssel: Champ Vallon, 2003.

86. KeRVILER, René y BARTHÉLEMY, Edouard. Valentin Conrart, premier secrétaire perpétuel de l'Académie Française, sa vie et sa correspondance. Paris: Didier, 1881, p. 89.

87. Rou, Jean. Mémoires inédits et opuscules de Jean Rou (1638-1711). Ed. F. Waddington. Paris: Agence Centrale de la Société, 1857, t. 2, p. 31.

88. El nombre de Félibien aparece por vez primera asociado a la Petite Académie en 1664 en un documento donde se detallaban los distintos gastos. Guiffrey, Jules. Comptes des Bâtiments du Roi sous le Règne de Louis XIV. Paris, 1881, t. I, p. 50. Sin embargo, no entró en ella oficialmente hasta 1683, una vez muerto Colbert. Perrault, Charles. Mémoires de Charles Perrault. Avignon, 1759, pp. 199-200.

89. Bonfait, Olivier. Rome-Paris, 1630-1680. Poussin et le grand format. Comment la France s'approprie l'idée de peinture. Thèse d'habilitation à dirigir des recherches. Paris: Université Paris IV Sorbonne, 2003.

90. Michel, Christian. "De l'Ekphrasis à la description analytique: histoire et surface du tableau chez les théoriciens de la France de Louis XIV». En RECHT, Roland (ed.). Le texte de l'oeuvre d'art. La description. Strasbourg: P.U. Strasbourg, 1998, pp. 45-56.

91. Lichtenstein, Jacqueline. "De l'idée de la peinture à l'analyse du tableau. Une mutation essentielle de la théorie de l'art». Revue d'Esthétique, 1997, 31/32, pp. 17-36. 
Le Brun se había sentido atraído desde su viaje a Italia por las grandes decoraciones de Cortona, como reflejará en el Hôtel Lambert y en sus proyectos del Louvre; y aunque la fascinación de los franceses por Cortona venía de lejos debieron conformarse, finalmente, con sus alumnos ${ }^{92}$. Romanelli dejó dos ejemplos de su arte en la Galería del Palacio de Mazarino y en los apartamentos de Ana de Austria en el Louvre ${ }^{93}$, que Le Brun tuvo muy en cuenta a la hora de afrontar sus trabajos en Vaux. Esta obra de Romanelli se había visto acompañada por un texto explicativo sobre los complejos discursos alegóricos, escrito por Ascanio Amalteo ${ }^{94}$, el cual sirvió de modelo a Félibien para dar forma a su discurso artístico, profundizando en la relación entre texto e imagen. La dimensión textual de la obra pictórica era fundamental porque permitía dirigir su recepción, controlando la lectura del espectador, como se observará en los ciclos decorativos de Vaux. En ellos, poder, texto e imagen se dieron la mano a través de la alegoría, mostrando la capacidad elocuente y persuasiva de la pintura; lo que sin duda impulsó a Colbert a revitalizar la Academia, apoyándose para ello en los hombres de letras de la Petit Académie, tal y como le aconsejaba Chapelain ${ }^{95}$. De este modo, Colbert, aprovechando los estatutos fundacionales de 1648 que todavía no habían sido aprobados por la inestabilidad política, afrontó en 1663 una auténtica refundación de la Academia, adscribiéndola a los trabajos de engrandecimiento de la monarquía.

Dès la fin de l'année 1662, M. Colbert ayant prévu on fachant déja que le roi le feroit surintendant de ses bâtimens, commença à se préparer à la fonction de cette charge [...] Il songea [...] faire élever beaucoup de monumens à la gloire du roi [...] Il voulu en conséquence assembler un nombre de gens de lettres [...] \& former une espece de petit conseil pour toutes les choses dépendantes des belles lettres. Il avoit déja jetté les yeux sur M. Chapelain qu'il connoissoit ${ }^{96}$.

La alegoría tuvo un lugar prioritario dentro de esta refundación, tal y como había sugerido Chapelain al propio Colbert $^{97}$, pero, también, ocupó un lugar

92. Laurain-Portemer, Madeleine. «Le Palais Mazarin à Paris et l'offensive baroque de 1645-1650. D'après Romanelli, P. de Cortone et Grimaldi». Gazette des beaux-arts, 1973, 81, pp. 151-168.

93. Milovanovic. Nicolas. "Romanelli à Paris : entre la galerie Farnèse et Versailles». En Bonfait. L'idéal classique..., pp. 85-139; OY-MARra, Élisabeth. "Mazarin et les fresques de Giovanni Francesco Romanelli dans l'appartement d'été d'Anne d'Austriche au Louvre». En ConiHout, Isabelle y MicheL, Patrick (coms.). Mazarin. Les lettres et les arts. Paris: Bibliothèque Mazarine, 2006, pp. 145-155.

94. BODART, Didier. "Une description de 1657 des fresques de Giovanni Francesco Romanelli au Louvre». Bulletin de la Société de l'Histoire de l'Art français, 1974, pp. 43-50.

95. «Pour en pas néantmoins laisser le Roy sans les louanges qu'il mérite, aussi bien en prose qu'en vers, je seroi d'avis qu'on employast les meilleures plumes à traitter ses miracles oratoirement par des panégyriques [...] Il y a bien, Monsieur, d'autres moyens louables de respandre et de maintenir la gloire de Sa Majesté». Chapelain, Jean. "Lettre CLV, de Chapelain à Colbert, Paris 18 novembre 1662». En Lettres de Jean Chapelain. Ed. P. Tamizey de Larroque. Paris: Imprimerie Nationale, 1863, t. II, pp. 276-277.

96. Perrault. Mémoires de Charles Perrault..., pp. 29-31.

97. "J'ay reçu avec respect la réponse qu'il vous a plu de faire à ma lettre touchant l'employ de l'allégorie dans les tableaux et les tapisseries [...] adresse pour porter M. Le Brun à en convenir avec 
privilegiado en la clasificación de los géneros pictóricos que hará Félibien, ya que permitía expresar esa dimensión intelectual y elevada de la pintura que reivindican los artistas frente al gremio, así como la posibilidad de adaptar la pintura al discurso del poder. Félibien buscaba alejarse de los textos teóricos de Fréart de Chambray o Dufresnoy, postulándose claramente a la dirección intelectual de la futura Academia, ya que era uno de los pocos que estaban en disposición de elaborar un discurso teórico que diese respuesta a las necesidades simbólicas de la monarquía; tal y como había subrayado en Le Songe de Philomate, de 1683, donde abogaba por el abandono de las disputas personales y por el trabajo conjunto entre poesía y pintura en favor de la grandeza del monarca ${ }^{98}$.

La redacción en 1663 de los nuevos estatutos de la Academia introdujo la figura del amateur honoraire, lo que permitió a Colbert inmiscuirse directamente en sus asuntos, situando a sus peones Du Metz y Charles Perrault, quien es recibido el 4 de junio en calidad de conseiller bonoraire amateur, asistiendo a las reuniones de la Academia de forma regular. Al observar que los debates teóricos se alejan de sus intenciones, Colbert decide dar un nuevo giro en 1666, viendo en los escritos de Félibien el ejemplo de lo que debería hacerse en la institución ${ }^{99}$, como refleja la carta enviada por Perrault a los académicos ante la visita de Colbert el 9 abril de $1667^{100}$. Félibien comenzó, así, a dirigir el proyecto de escritura y publicación de las conferencias, apartando a Testelin, y produciendo un conflicto de intereses entre Colbert y los académicos.

La introducción de las nuevas ideas en la Academia llevada a cabo por Félibien, a partir de las conferencias presentadas por los académicos, se observa claramente en su Préface, donde irrumpen cuatro temas que no aparecen desarrollados en el resto de las conferencias, demostrando su autoría ${ }^{101}$. Primero, la distinción entre arte y artesano, germen del nacimiento de la Academia. Segundo, la separación de las partes de la pintura en teóricas y prácticas, que justificaría la

nous et à ne gouster pas moins nos raisons qu'elle et vous les avez goustées». CHAPELAIN, Jean. "Lettres de Chapelain a Colbert, Lettre n. ${ }^{\circ}$ 8, Paris, 10 juin 1664». En Lettres, Instructions et Mémoires de Colbert. Ed. P. Clement. Paris: Imprimerie Impériale, 1868, t. V, p. 596.

98. FÉLIBIEN, André. "Le Song de Philomathe». En Recueïl de Descriptions de Peinture et d'autres ouvrages faites pour Le Roy. Paris: Sebastien Mabre-Cramoisy, 1689, p. 499.

99. GERMER, Stefan. Art-Pouvoir-Discours. La carrière intellectuelle d'André Félibien dans la France de Louis XIV. Paris: FMSH, 2016, p. 309.

100. "Mais comme l'employ de rédiger ces conférences par escrit est très vaste et très pénible, il ne parait juste d'exiger de Mr. Testelin [...] Dans le besoin de trouver une plume digne de cette occupation, il semble que la Compagnie aurait à souhaiter que Mr. Félibien, [...] il a ce semble une obligation particulière d'ecrire de cequi se passe dans l'Académie, dont le but principal est de s'occuper à embellir ces mesmes bastimens et à fournir de matière aux belles descriptions qu'il est obligé d'en donner au public». COlBERT. "Projet de l'ordre qui se pourroit tenir dans l'Académie Royale... touchant les Conférences..., le 28 mars 1667». En Procès-verbaux de l'Académie Royale de Peinture et de Sculpture, 1648-1792. Ed. A. Montaiglon. Paris: J. Baur, 1875, t. I, p. 316.

101. Germer. Art-Pouvoir-Discours..., pp. 315 y s. 
irrupción dentro de la institución de amateurs como él. Tercero, la teoría de los modos musicales aplicada a la pintura, elaborada por Poussin y recogida por Le Brun. Cuarto, la clasificación y jerarquía de los géneros ${ }^{102}$. En relación a esta última en su Préface encontramos tres tipos de clasificaciones diferentes, que recogerán, a su vez, las principales oposiciones sobre las cuales se han definido las distintas clasificaciones desde el Renacimiento: alto/bajo, ideal/real, animado/inanimado.

En primer lugar, nos encontramos una ordenación en la que establece siete partes de la pintura, siguiendo una clasificación tradicional establecida por el humanismo a partir del discurso del orador: inventio, dispositio y elocutio.

En segundo lugar, otra clasificación que distinguirá entre artes liberales y artes mecánicas, esto es, entre el artesano y el artista. Se considera que la pintura debía superar las partes menos nobles o bajas propias del artesano para alcanzar una dimensión elevada del pensamiento, como mostraba la Poesía o la Historia: "Cependant la Peinture en este un bien plus élevé, \& qui a cela pardessus les plus célebres, qu'en formant des pensées aussi hautes, \& tratans les mêmes sujets que l'Histoire \& la Poësie» ${ }^{103}$. Retomaba así los debates italianos acerca de la aspiración de la pintura a la idea y a la dimensión intelectual ${ }^{104}$.

L'on fera donc voir que non seulement le Peintre est un Artisan incomparable, en ce qu'il imite les corps naturels \& les actions des hommes, mais encore qu'il est un Auteur ingenieux \& sçavant, en ce qu'il invente \& produit des pensées qu'il n'emprunte de personne. De sorte qu'il a cét avantage de pouvoir représenter tout ce qui est dans la nature, \& ce qui s'est passé dans le monde, \& encore d'exposer des choses toutes nouvelles dont il est comme le createur ${ }^{105}$.

Es en esta segunda clasificación cuando irrumpe la cuestión del género. Aunque Félibien empleará la noción de sujets o temas ${ }^{106}$, buscando dar un sentido más analítico, alejándose de la noción de género como estilo retórico, más dado a la subjetividad, al ser de carácter evaluativo. Se aproximaba, con ello, a la Poética de Aristóteles, donde la nobleza del tema dependería de la complejidad a la hora de imitarlo, y no como en la retórica al estilo de representarlo. Es por ello que se centra en los objetos imitados, esto es, sobre los temas, lo que le permite establecer una clasificación y una jerarquía nítida.

102. Ibid., pp. 316-317.

103. FÉlibien, André. "Préface». En Conférences de l'Academie Royale de Peinture et de Sculpture. Amsterdam: Estienne Roger, 1706, p. 14.

104. "Un Art tout particulier qui est détaché de la matiere \& de la main de l'Artisan, par lequel il doit d'abord former ses Tableaux dans son esprit». Ibid., p. 15.

105. Ibid., p. 17.

106. El término género lo encontramos ya en algunos tratadistas italianos desde el siglo XVI como Paolo Giovio (Barocchi, Paola. Scritti d'arte del Cinqucento. Milano: Riccardo Ricciardi, t. I, p. 18). Se trataría de un término que entra en Francia en el siglo XVI, siendo frecuente en Ronsard (NAïs, Hélène. "La notion de genre en poésie au XVII : étude lexicológique et sémantique». En DemerSON, Guy [ed.]. La notion de genre à la Renaissance. Genève: Slatkine, 1984, pp. 103-127). 
A partir de esta contraposición entre naturaleza/idea, establece una jerarquía que comenzaría con el arte más sencillo, apegado a la materia: "La représentation qui se fait d'un corps en traçant simplement des lignes, ou en mêlant des couleurs est considerée comme un travail méchanique ${ }^{107}$, que recordaría a Alberti y a Pous$\sin ^{108}$. Este arte iría complejizándose a través de la representación de la naturaleza inanimada: "Il est constant qu'à mesure qu'ils s'occupent aux choses les plus difficiles \& les plus nobles, ils sorten de ce qu'il y a de plus bas y de plus commun»109; como son las representaciones de frutas, flores y conchas, que culminarían en el paisaje: "Ainsi celui qui fait parfaitement des paisages est au dessus d'un autre qui ne fait que des fruits, des fleurs ou de coquilles»" ${ }^{10}$. A continuación se dará paso a la naturaleza animada, centrada en la representación del Hombre, en tanto que la obra más perfecta creada por Dios. Comenzaría por el retrato, para dar lugar a la representación de los cuerpos humanos en acción, capaces de expresar pasiones e ideas complejas.

Celui qui peint des animaux vivans est plus estimable que ceux qui ne représentent que des choses mortes \& sans mouvement; \& comme la figure de l'homme est le plus parfait ouvrage de Dieu sur la terre, il est certair, aussi que celui qui se rend l'imitateur de Dieu en peignant des figures humaines, est beaucoup plus excellent que tous les autres ${ }^{111}$.

Puesto que más allá de la Naturaleza está la Idea, Félibien distingue entre los retratos de hombres y la representación de los hombres en movimiento, dando de nuevo una importancia esencial a la acción: "Cependant quoi que ce ne soit pas peu de chose de faire paroître comme vivante la figure d'un homme, \& de donner l'apparence du mouvement à ce qui n'en a point; néamoins un Peintre qui ne fait que des portraits, n'a pas encore atteint cette haute perfection de l'art „12. Sin embargo, todavía por encima de esta sitúa la alegoría, que permitiría añadir, a la representación de los cuerpos en acción, ideas y discursos complejos: "Il faut représenter de grandes actions comme les Historiens, ou des sujets agréables comme les Poëtes; \& montant encore plus haut, il faut par des compositions allegoriques, sçavoir couvrir sous le voile de la fable les vertus des grands hommes, \& les mysteres les plus relevez ${ }^{113}$. Con ello lograba demostrar la utilidad de la pintura respecto al proyecto de engrandecimiento de la monarquía a través de

107. FÉLIBIEN. "Préface...», p. 16.

108. Poussin, Nicolas. "Carta a Chambray, Roma 1 de marzo de 1665". En Cartas y consideraciones en torno al arte. Ed. A. Blunt. Madrid: Visor, 1995, p. 140.

109. FÉLiBIEN. "Préface...", p. 16.

110. Ibid.

111. Ibid.

112. Ibid.

113. Ibid. 
la alegoría: «Ou quelques allegories, qui sont les sujets les plus sublimes, \& qui comme les plus excellens comprennent tous les autres ${ }^{114}$.

Félibien concluye esta segunda clasificación siguiendo, literalmente, la distinción aristotélica entre medios, objetos y modos de representación, que denomina cuerpos, acciones y maneras de imitar: "Cet Art se divise en plusieurs parties, soit à cause de la diversité des corps \& des actions que l'on imite, soit à cause de la differente maniere de les imiter ${ }^{115}$. Esta clasificación aglutina y recoge, a su vez, el conjunto de la clasificación que acabamos de analizar. La clasificación según los medios de representación la encontramos en el siguiente párrafo: "La représentation qui se fait d'un corps en traçant simplement des lignes, ou en mêlant des couleurs est considerée comme un travail méchanique» ${ }^{116}$. La pintura puede dividirse así en función de sus medios, esto es, de líneas y colores. A continuación, y según el objeto de representación, Félibien considera que es la mímesis de los distintos sujetos de la naturaleza lo que define la pintura: "Differens sujets; il est constant qu'à mesure qu'ils s'occupent aux choses les plus difficiles \& les plus nobles, ils sortent de ce qu'il y a de plus bas \& de plus commun ${ }^{117}$. Se refiere así a los tipos de objetos: flores, paisajes u hombres. Finalmente, y en relación a los modos de representación, Félibien hablará de la mímesis animada o inanimada, inclinándose por la representación de los hombres en acción: «Il faut représenter de grandes actions comme les Historiens" ${ }^{118}$.

En tercer lugar, encontraremos un último tipo de clasificación que volvería a generar una nueva jerarquía, al dividir la pintura entre una dimensión teórica y otra práctica: "C’est pour cela que je dirai qu'il a deux parties principales á considerer, l'une qui regarde le raissonnement ou la theorie, l'autre qui regarde la main ou la pratique ${ }^{119}$. Pese a remarcar la importancia de la dimensión práctica, probablemente con la intención de no enemistarse con los académicos, la considera como inferior ${ }^{120}$, legitimando, así, la función del amateur en la Academia.

La jerarquía de los géneros propuesta por Félibien se construía en función del tema y no de su tratamiento estilístico, lo cual le facilita la clasificación de la pintura, adaptándola mejor a las necesidades simbólicas de la monarquía al evitar los equívocos o malas interpretaciones, ya que reducía la subjetividad del juicio propio de los estilos retóricos (ya que en este lo que puede ser elevado para unos puede ser bajo para otros). Es, por ello, que las escenas cotidianas (definidas, como se ha visto, en función del estilo bajo e identificadas con la comedia) desaparecen de su escrito, pues, este tipo de pintura muestra su particularidad

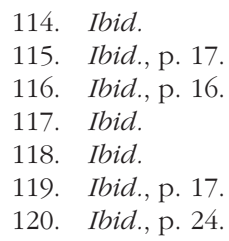


cuando se enjuicia no en función del objeto imitado o tema, sino del tono o estilo. Razón por la cual, cuando se refiere a ellas, lo hará de forma negativa, pues, a pesar de tratar la figura humana, no hay historia en ellas, limitándose a imitar y no a representar ${ }^{121}$. Esta clasificación temática le permitía clasificar la producción visual y pictórica de una forma aparentemente coherente y sencilla, en función de la complejidad intelectual del arte, facilitando su recepción y enjuiciamiento. Pero, también, permitía establecer jerarquías entre los propios creadores, esto es, entre aquellos que ejercían la pintura de historia y aquellos otros que practicaban otros tipos de pintura; siendo esta jerarquía la culminación del proceso de intelectualización y textualización de la imagen iniciada en Italia.

Esta jerarquía temática era, asimismo, una trasposición de la jerarquía social $^{122}$, tal y como se había puesto de manifiesto en los textos teóricos teatrales ${ }^{123}$. Los géneros pictóricos determinaban, por tanto, la organización y jerarquía interna de la institución académica, por ejemplo, a la hora de la distribución de cargos, como se reflejaba en los estatutos de 1663: "Que nulle personne à l'avenir ne sera receuè en ladite Charge de Professeur qu'il n'ait esté nommé Ajoint, qu'il n'ait fait connoistre sa capacité en la figure et en l'histoire» ${ }^{124}$; o a la hora de disponer los asientos en la Sala de la Asamblea ${ }^{125}$. El pintor de historia tenía una serie de privilegios que revelaban una jerarquía social interna, similar al gremio, determinando los ascensos y los privilegios, facilitando, finalmente, el gobierno de la institución. Funcionaba, por tanto, de forma similar a como lo hacían otras instituciones recién reformadas por Colbert y Le Tellier, así como la propia corte. La jerarquía era la forma de organización habitual de la sociedad en el Antiguo Régimen ${ }^{126}$, por lo que la institución académica incorporó para su gobierno interno los mismos mecanismos que funcionaban en la sociedad, legitimándolos, además, mediante una serie de clasificaciones donde se privilegiaba el género histórico, que, a su vez, legitimaba al soberano.

A pesar de que el Préface fortalecía la posición predominante de Le Brun en la Academia al encumbrar la alegoría y la expresión pictórica, sin embargo, otorgaba también excesivo peso a las "criaturas» de Colbert, tal y como se quejaba Le Brun a propósito de Félibien ${ }^{127}$, quien controlaba el proyecto discursivo de la

121. Ibid., p. 22.

122. ViteT, Ludovic. L'Académie Royale de Peinture et de Scupture. Paris, 1861, pp. 261 y s.; Michel. L'Académie Royale..., pp. 48 y s.

123. "C'est pour cela même que nous voyons dans la Cour de France les Tragédies mieux reçues que les Comédies, et que parmi le petit Peuple les Comédies et mêmes les Farces et vilaines bouffonneries de nos Théâtres sont tenues plus divertissantes que les Tragédies (II, 1)». D'AuBignac, François. La pratique du théatre. Amsterdam: Frederic Bernard, 1715, t. I, pp. 64-65.

124. Artículo XIII. VITET. L'Académie Royale..., p. 265.

125. Artículo XXI. VITET. L'Académie Royale..., p. 268.

126. Mousnier, Roland. Les Hiérarchies Sociales, de 1450 à nos jours. Paris: PUF, 1969, p. 7.

127. Rou. Mémoire inédits..., t. 2, p. 31. 
Academia. Razón por la cual los académicos maniobraron para supeditar a Félibien a los órganos internos de la institución ${ }^{128}$. El 20 de abril de 1669, la Academia reunida, en sesión extraordinaria y en presencia de Colbert, discute la edición publicada por Félibien, y ante las quejas Colbert tendrá que ir en contra de su protegido, concediendo a la Academia el derecho de reescribir las conferencias y corregir los defectos que considerasen, delegando en la asamblea el control de las publicaciones ${ }^{129}$. El 25 de enero de 1670, Le Brun propone confiar a Testelin la tarea de dirigir los procesos verbales de las conferencias, apartándose definitivamente a Félibien. Fuera ya de la institución, este mantendrá su clasificación en sus Entretiens, demostrando su utilidad a la hora de hablar y enjuiciar el arte; y, aunque reconocía ahora la perfección técnica alcanzada por los distintos géneros, en líneas generales los consideraba como inferiores a la pintura de historia, reafirmándose en su jerarquía.

Les Peintres qui traitent des histoires \& des sujets les plus nobles, doivent estre plus estimez que ceux qui ne representent que des païsages, ou des animaux, ou des fleurs, ou des fruits, ou des choses encore moins considerables: cependant on le laisse pas parmi ces derniers d'en rencontrer qui ont tant d'habilité [...] qu'il est bien plus facile de representer ces sortes d'objets qu'on peut dire inanimez pour la pluspart, \& sans actions ${ }^{130}$.

Félibien emplea la noción de género en un sentido prescriptivo-normativo, como es frecuente desde el cinquecento, mostrando una actitud clasificatoria que volveremos a encontrar en Charles Perrault ${ }^{131}$ o en Roger de Piles, y que se mantendrá a lo largo del siglo XVIII.

Les Peintres se servent avec raison du mot d'histoire pour signifier le genre de Peinture le plus considérable, et qui consiste à mettre plusieurs figures ensemble; et l'on dit: ce Peinture fait l'histoire, cet autre fait des animaux, celui-ci du Paysage, celui-là des fleurs, et ainsi du reste. Mais il y a de la différence entre la division des genres de Peinture et la division de l'invention. Je me sers ici du mot d'histoire dans un sens plus étendu; j'y comprends tout ce qui peut fixer l'idée du Peintre, ou instruire le spectateur ${ }^{132}$.

Piles apuntaba hacia una gran clasificación entre pintura de historia y el resto, cuestionando, sin embargo, que la división se realizase en torno a la narración, como había propuesto Félibien, subrayando que podían existir grandes pinturas

128. Procès-verbaux de l'Académie..., pp. 331-332.

129. Ibid., p. 339.

130. FÉLIBIEN, André. "Dixième Entretien». En Entretiens sur les vies et les ouvrages des plus excellens peintres anciens et modernes. Paris, 1666-1688, 5 vols., t. V, pp. 255-258.

131. Perrault, Charles. «La Peinture». En Recueil de divers ouvrages en prose et en vers. Paris: Jean Baptiste Coignard, 1676, pp. 192-194.

132. PILEs, Roger de. Cours de peinture pour principes. Paris: Jacques Estienne, 1708, pp. 53-54. 
que no narrasen historias ${ }^{133}$, prefiriendo una división en torno a la invención; mostrando interés por géneros hasta ahora considerados como inferiores, como el paisaje o el retrato.

En 1690 el Dictionnaire de Furetière, así como el Nouveau Dictionnaire de Richelet de 1694 -que estarán en la base del Dictonnaire de Trévoux-, definirán el término 'género' siguiendo las nociones de esencia o eidos que había empleado Aristóteles, ofreciendo dos acepciones. En primer lugar, en sus reflexiones sobre la vida orgánica y la substancia, emplea la noción de género en el sentido de una clasificación en árbol que diferencia entre género y especie ${ }^{134}$, como había apuntado Félibien cuando señalaba que el género histórico comprendía el resto de géneros y de ahí su superioridad. Idea que volveremos a leer en Du Bos y Diderot. En la segunda acepción, ofrece una descripción tradicional de género en el sentido de tipo o clase.

Du Bos empleará el término "género", también, con un sentido de clase ${ }^{135}$, siendo el principio ordenador de su clasificación la emoción causada en el espectador a través de la representación de las pasiones: «Et chaque genre nous touche à proportion que l'objet, lequel il est de son essence de peintre et d'imiter, est capable de nous émouvoir» ${ }^{136}$. Considera que hay determinadas imitaciones que se quedan simplemente en lo ordinario, como las escenas del norte de Europa, las cuales pueden llamar la atención por su perfección técnica ${ }^{137}$, pero que no serían capaces de emocionar al espectador, porque no se construyen ni sobre la acción ${ }^{138}$ ni sobre la capacidad expresiva, así como, tampoco, sobre la representación de las pasiones, como sí encuentra en la pintura de historia.

En 1747 aparecerán las Réflexions de La Font de Saint-Yenne, que coincidirán con la consolidación de las exposiciones públicas de pintura. Saint-Yenne hablará, igualmente, de distintos géneros en pintura, defendiendo la superioridad de la pintura de historia sobre el resto, de acuerdo a su concepción expresiva del arte;

133. "A quoy on répond, que si la fidélité de l'Histoire étoit essentielle à la Peinture, il n'y auroit point de Tableau où elle ne dût se rencontrer: Or il y a une infinité de beaux Tableaux qui ne réprésentent aucune Histoire». PILEs, Roger de. "L’idée du Peintre parfait». En Abrégé de la vie des peintres. Paris: François Muguet, 1699, pp. 28-29.

134. Furetière, Antoine. Dictionnaire Universelle. 2. ${ }^{\text {a }}$ edición. La Haya: Arnould et Reinier Leers, 1702 , t. 1 , p. 1004.

135. Du Bos. «Deuxième Partie. Section 7». En Réflexions critiques sur la poésie et sur la peinture. Paris: ESBA, 1993, p 194.

136. Du Bos. «Première Partie. Section 8». En Du Bos. Réflexions critiques..., p. 21.

137. Du Bos. "Première Partie. Section 10». En Du Bos. Réflexions critiques..., p. 24.

138. "Il n'est rien dans l'action d'une fête de village [...] qu'elle peut bien nous faire applaudir aux talents que l'ouvrier avait pour l'imitation, mais elle ne saurait nous toucher». Du Bos. "Première Partie. Section 6». En Du Bos. Réflexions critiques..., p. 18. 
y, aunque admitía la perfección alcanzada por otros géneros ${ }^{139}$, consideraba las escenas cotidianas como inferiores ${ }^{140}$.

De tous les genres de la Peinture, le premier sans difficulté est celui de l'Histoire. Le Peintre Historien est seul le Peintre de l'âme, les autres ne peignent que pour les yeux. Lui seul peut mettre en oeuvre cet enthousiasme, ce feu divin qui lui fait concevoir ses Sujets d'une manière forte et sublime ${ }^{141}$.

Watelet definió el género en pintura también como clase, y la pintura de género, específicamente, como aquello que no era pintura de historia, identificándola con aquellos que poseen un talento limitado.

Le mot de genre adapté à l'art de la Peinture, sert proprement à distinguer de la classe des peintres d'histoire, ceux qui bornés à certains objets, se font une étude particulière de les peindre, et une espèce de loi de ne représenter que ceux-là: ainsi l'artiste qui ne choisit pour sujet de ses tableaux que des animaux, des fruits, del fleurs ou des paysages, est nommé peintre de genre ${ }^{142}$.

Lacombe señala que "le genre Historique est le plus considérable en Peinture» ${ }^{143}$; y el abbé Marsy describe la pintura de historia como «le plus noble et le plus dificile» ${ }^{144}$. Pernety subraya que hay diversos géneros y considera que existe una pintura elevada y otra baja, que identifica con la pintura del norte de Europa $^{145}$.

Diderot, en la línea de la reflexión artística de su época ${ }^{146}$, pensará la pintura en paralelo a la poesía: "Il me semble qu'il y a autant de genres de peinture que de genres de poésie». Aunque, más adelante, parece considerar esta trasposición como problemática ${ }^{147}$, concluyendo que las clasificaciones parecen ser «une division

139. LA FONT DE SAINT-YEnNE, Étienne. "Sentiments sur quelques ouvrages de peintre, sculpture et gravure, 1754». En Oeuvre Critique. Éd. E. Jollet. Paris: ESBA, 2001, p. 298.

140. Ibid., p. 299.

141. La Font De SAinT-Yenne, Étienne. «Réflexions sur quelques causes de l'État présent de la peinture en France». En LA FonT DE SAInT-Yenne. Oeuvre Critique..., p. 47.

142. Watelet, Claude-Henri. "Genre (peinture)». En Diderot, Denis y D'Alembert, Jean le Rond. Encyclopédie. Paris: Briasson, 1757, t. VII, pp. 597-598.

143. Lacombe, Jacques. "Historique». En Dictionnaire portatif des Beaux Arts... Paris: Herissant et Estienne, 1752, p. 323.

144. MARSY, François-Marie. "Historia». En Dictionnaire abrégé de peinture et d'architecture... Paris, 1746 , pp. 304-305.

145. PERNETY, Antoine-Joseph. "Balancer». En Dictionnaire portatif de peinture, sculpture et gravure. Genève, 1757, p. 22.

146. Rosenberg, Pierre. "Diderot, critique d'art conformiste». Commentaire, 1985, 30, pp. 683-687; MORTIER, Roland. "Diderot et le "grand goût", ou le prestige de la peinture d'histoire au XVIII siècle». En Le Coeur et la Raison. Recueil d'études sur le dix-huitième siècle. Paris: Éditions de l'Université de Bruxelles, 1990, pp. 168-191.

147. SEZnec, Jean. Essai sur Diderot et l'Antique. Oxford: Clarendon Press, 1957, pp. 57-58; DEMORIS, René. «Utpictura poesis? Quelques aspects du rapport roman-peinture au siècle des Lumières". 
superflue» ${ }^{148}$, pues, como había señalado Watelet: «genres en pinture se sont divisé \& peuvent se subdiviser à l'infini» ${ }^{149}$. Consideraba que una pintura debía emocionar y conmocionar al espectador, captando su atención a través, por un lado, de la técnica, donde todos los géneros podían alcanzar la perfección ${ }^{150}$; y, por otro lado, de la temática, mediante la representación de las pasiones humanas: "C'est qu'il y a deux sortes d'enthousiasme, l'enthousiasme d'âme et celui du métier. Sans l'un le concept est froid; sans l'autre l'exécution est faible; c'est leur union qui rend l'ouvrage sublime ${ }^{151}$. Respecto a esta última -la temática- no todos los géneros se mostraban igual de capacitados, mostrándose como superior la pintura histórica.

Diderot también valoraba aquellas pinturas que despertaban la imaginación del espectador ${ }^{152}$, permitiéndole introducirse en el cuadro, como los paisajes de Vernet, las pinturas de ruinas de Robert o las escenas morales de Greuze. Estos géneros o clases se revalorizarán en sus escritos, criticando la actitud despectiva de ciertos pintores de historia que despreciaban el resto, pese a que ellos mismos habían caído en el amaneramiento ${ }^{153}$, como había criticado también Du Bos ${ }^{154}$; defendiendo un aprendizaje a partir de la Naturaleza, que recordará al vrai composé de Roger de Piles. Será a través de esta verdad natural que Diderot buscará redefinir la clasificación y la jerarquía de las artes propuesta hasta ahora, lo que le permitirá poner en paralelo la obra de Greuze o Chardin y la gran pintura de historia: "Ah si un sacrifice, une bataille, un triomphe, une scène publique pouvait être rendu avec la même vérité dans tous ses détails qu'une scène domestique de Greuze ou de Chardin!»155. No obstante, inmediatamente, y como si temiese poner en cuestión el canon establecido, parece retroceder para reconocer la superioridad del pintor de historia al no trabajar sobre un modelo visible y ser por ello más compleja ${ }^{156}$.

En Lafarge, Catherine (ed.). Dilemmes du roman. Essays in honour for G. May. Anma Libri, 1965, pp. 296-281. Stanford French and Italian Studies, 65.

148. Diderot, Denis. «Essais sur la peinture». En Essais sur la peinture, Salons de 1759, 1761,

1763. Ed. G. May. Paris: Hermann, p. 65.

149. WATELET. "Genre...", p. 599.

150. "Mais en laissant aux mots les acceptions reçues, je vois que la peinture de genre a presque toutes les difficultés de la peinture historique». DiDEROT. "Essais sur la peinture...», p. 67.

151. Diderot. "Essais sur la peinture...", p. 396.

152. «La raison en este que l'imagination y supplée toutes les parties qui y manquent, ou qui n'y sont pas terminées \& que chacun les voit selon son Goût». PILES. «Idée du Peintre parfait...» p. 70.

153. DidEROT. "Essais sur la peinture...», pp. 65-66.

154. "Tel peintre demeure confondu dans la foule [...] Mais ne vaut-il pas mieux être un des premiers parmi les paysagistes que le dernier des peintres d'histoire?». Du Bos. «Deuxième Partie. Section 7». En Réflexions critiques..., p 194.

155. DIDEROT. "Essais sur la peinture...», p. 63

156. "C'est sous ce point de vue surtout, que le travail du peintre d'histoire est infiniment plus difficile que celui du peintre de genre». Ibid., p. 63. 
Diderot, además de la complejidad, también señala como principio de clasificación la separación entre naturaleza inanimada y pintura animada ${ }^{157}$, tal y como habían hecho Félibien o Roger de Piles, adscribiendo la pintura de historia a todo aquello que imita la naturaleza sensible y viva; y, de este modo, si bien distingue entre pintura de historia y pintura de género, sin embargo, piensa que esta última noción era excesivamente amplia y, por tanto, señalaba que autores como Greuze no podían ser considerados como simples pintores de género ${ }^{158}$. De este modo, buscará ampliar la noción de pintura de historia volviendo a la definición tradicional, como aquella que simplemente narra una historia (como se venía definiendo desde Leonardo), frente a aquella otra acepción que se refería a la representación de hombres ilustres. Defiende una imitación fundamentada en lo verdadero y en la naturaleza directamente observada, animando a los pintores a salir a las calles y a pintar las expresiones y pasiones que en ellas acontecen ${ }^{159}$. Pero, como en el vrai composé de Roger de Piles, esta verdad deberá estar trabajada ${ }^{160}$ para poder alcanzar la perfección que caracteriza al pintor de historia, imposibilitando, con ello, cualquier tipo de lectura en clave objetiva o realista de sus textos.

A pesar de aceptar la clasificación entre pintura de historia y pintura de género -donde se englobaba el resto-, insistirá en la idea de que ambas tienen un denominador común: «animer les choses mortes»" ${ }^{161}$, de acuerdo a su idea de energía. De este modo, su reivindicación de las obras de Greuze deberemos entenderla no tanto como una reivindicación de la pintura de género -que no era un término bien definido-, sino, más bien, como un intento de sacar a Greuze de aquella clasificación, ya que para él su pintura narraba una historia y buscaba representar emociones. Razón por la cual, y de acuerdo al modelo clasificatorio predominante desde el cinquecento, Diderot creará un nuevo tipo o género para describir la pintura de Greuze, como había hecho Castelvetro en poesía: la pintura moral ${ }^{162}$.

157. «Voici ce que c'est. La nature a diversifié les êtres en froids, immobiles, non vivants, non sentants, non pensants, et en êtres qui vivent, sentent et pensent [...] Il fallait appeler peintres de genre les imitateurs de la nature brute et morte; peintres d'histoire les imitateurs de la nature sensible e vivante; et la querelle était finie». Ibid., p. 67.

158. "Il me semble que la division de la peinture en peinture de genre et peinture d'histoire est sensée, mais je voudrais qu'on eût un peu plus consulté la nature des choses dans cette division". Ibid., pp. 66-67.

159. "C'est ajourd'hui veille de grande fête; allez à la paroise, rodez autour des confessionnaux et vous verrez la véritable attitude [...] et vous verrez l'action vraie de l'homme [...] Cherchez les scènes publiques». Ibid., p. 16.

160. "La figure sera sublime, non pas quand j'y remarquerai l'axactitude des proportions, mais quand j'y verrai tout au contraire un système de difformités bien liées et bien nécessaires». Ibid., pp. 74-75.

161. Ibid., p. 68.

162. "C'est la peinture morale». Diderot, Denis. "Salon de 1763». En Diderot. Essais sur la peinture..., p. 234. 
Si bien algunos autores del siglo XVIII criticarán la separación entre géneros: «Tombez, murailles, qui séparez les genres» ${ }^{163}$, sin embargo, la sociedad dieciochesca los valorará, en general, como una herramienta fundamental para pesar, producir y enjuiciar el arte, de acuerdo a la actitud clasificatoria de tipo normativo-prescriptivo dominante desde el cinquecento, defendiendo, por ello, la superioridad de la pintura de historia: «Un grand peintre d'histoire est un homme qui doit avoir beaucoup étudié. On ne le devient pas impunément ni par hasard ${ }^{164}$. En ningún momento se empleó la noción de género en un sentido esencialista, sino como tipo o clase, empleando el término pintura de género como aquello que no era pintura de historia, sin adscribir aquella, en exclusiva, a las escenas de la vida cotidiana. Además, no mostraron especial atención a este tipo de pintura, como si de algo novedoso u original de la época se tratase, relacionándola a menudo con la pintura flamenca tradicional.

163. MERCIER, Louis-Sébastien. Du Théâtre, ou nouvel essai sur l'art dramatique. Amsterdam, 1773 , p. 105.

164. Mercier, Louis-Sébastien. Fragmento sin título. Paris: Bibliothèque de l'Arsenal, MS 15083, f. 1. Citado por LedBury, Mark. "Hierarchy or Opposition? Understanding genre in Eighteenth-Century France». En LEDBURY, Mark (ed.). Sedain, Greuze, and the Boundaires of Genre. Oxford: Voltaire Foundation, 2000, p. 195. 
